
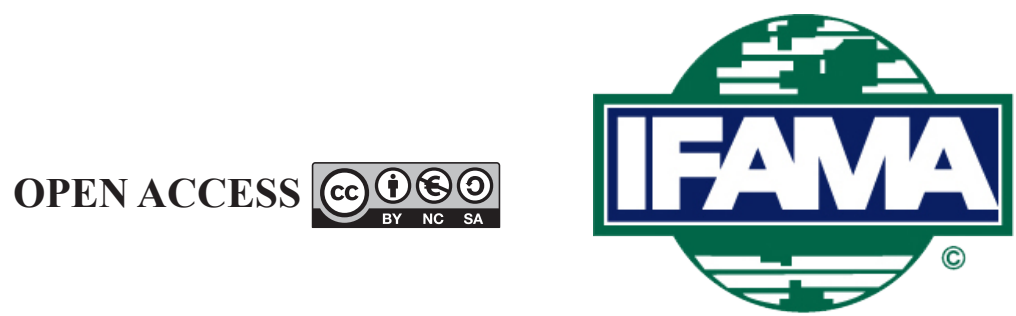

International Food and Agribusiness Management Review

Volume 23, Issue 4, 2020; DOI: 10.22434/IFAMR2019.0203

Received: 3 December 2019 / Accepted: 25 June 2020

\title{
Consumer preferences for wild game cured meat label: do attitudes towards animal welfare matter?
}

\section{RESEARCH ARTICLE}

\author{
Maria Elena Marescotti ${ }^{\oplus a}$, Vincenzina Caputo ${ }^{\mathrm{b}}$, Eugenio Demartini ${ }^{\mathrm{c}}$ and Anna Gaviglio ${ }^{\mathrm{d}}$ \\ ${ }^{a}$ Research fellow, ${ }^{c}$ Associate Professor, ${ }^{d}$ Full Professor, Department of Health, \\ Animal Science and Food Safety, University of Milan, Via dell'Università 6, 26900 Lodi, Italy \\ ${ }^{b}$ Assistant Professor, Department of Agricultural, Food, and Resource Economics, Michigan State \\ University, 446 W. Circle, Dr., Morril Hall of Agriculture, East Lansing, MI 48824, USA
}

\begin{abstract}
Even though the European Union has imposed a mandatory labeling system for conventional meats, there is no mandatory labelling scheme for the so called 'minor meats' - such as hunted wild game meat (HWGM). Thus, some European countries have implemented voluntary labelling programs certificating the origin of wild game meat. This study uses a discrete choice experiment to: (1) assess consumer preferences for processed meat products (including wild game meat bearing a HWGM label); and (2) investigate whether consumers' attitudes towards animal welfare affects their food choice behavior for alternative meat products. Data was collected through an online survey conducted in Italy and consumer preferences for HWGM was estimated through a latent class logit model. Overall, results suggest that, even though HWGM label does not exist yet on the Italian market, it is appealing to Italian consumers and it will likely be accepted by the majority of them. However, consumers who are particularly concerned about animal welfare issues and animal rights showed the lowest level of the interest in the hunted game meat product and thus the presence of the HWGM label does not provide any benefit to them. Our findings have important implications for the development of successful marketing strategies and policy intervention in the HWGM sector at a national and European level.
\end{abstract}

Keywords: consumer meat preferences, hunting, animal welfare scale, food labels, choice experiments JEL code: Q13, Q18, Q2

\footnotetext{
(1)Corresponding author: maria.marescotti@unimi.it
} 


\section{Introduction}

Due to the history of European food safety crises and livestock disease (such as the Bovine Spongiform Encephalopathy crisis, swine fever virus, and avian influenza), attributes such as origin, traceability, and/or processing practices have become consumers' prime concerns when purchasing meat products (Verbeke, 2001; Verbeke and Ward, 2006). In order to address the food safety concerns, the European Union (EU) imposed a mandatory labeling system for beef (Regulation (EC) No 1760/2000 (EC, 2000) and 1337/2013 (EC, 2013)), swine, sheep, goats, and poultry (Regulation (EC) No 1337/2013 (EC, 2013)) products. However, there is no mandatory labelling scheme for the so called 'minor meats' (EC, 2014). These 'minor meats' include meats such as hunted wild game meat (HWGM). As of recent, there have been efforts from European countries to implement voluntary labeling programs to track and certify wild game meat (Marescotti et al., 2019).

In line with the regulations already introduced by its neighbors, Italian businesses in the wild game supply chain are also attempting to develop voluntary labelling programs for HWGM products (Demartini et al., 2018; Marescotti et al., 2019; Viganò et al., 2019). The development of a labeling program for HWGM products is expected to raise consumer awareness and knowledge about minor meat products. Moreover, the labeling program will empower consumers to make informed purchasing decisions and form expectations about meat quality (Bernués et al., 2003; Grunert, 2006; Henchion et al., 2014). However, the development of such a labeling program will not only require high investments but will also incur additional future marketing costs for the producers (Banterle and Stranieri, 2008; Choi et al., 2018; Demartini et al., 2017). Therefore, the implementation of a new labeling program should be preceded by an evaluation of consumer preferences and willingness-to-pay (WTP) for HWGM products (Grunert, 2005; Merlino et al., 2018; Toma et al., 2012). Once the consumers' WTP are known, then retailers can accurately judge the feasibility of implementing this new labeling system.

Prior research has shown that hunting can be considered a sustainable management tool for controlling wildlife populations (Arnett and Southwick, 2015). For instance, good hunting practices may provide a new source of income for local communities (Gaviglio et al., 2017; Thogmartin, 2006), reduce the impacts wild animals have on agriculture (Giacomelli et al., 2018), and offer an environmentally sustainable alternative to current meat products (Fiala et al., 2020). Despite these benefits, consumers still form negative views on hunting, hunters, and hunting practices (Byrd et al., 2017; Demartini et al., 2018; Giacomelli and Gibbert, 2018; Ljung et al., 2012; Marescotti et al., 2019). These negative views may cause consumers to think negatively about HWGM (and by proxy the labeling implementation). This opposition to HWGM labels will be especially strong amongst people with animal welfare (AW) concerns. Thus, there remains some uncertainty as to if consumers will purchase HWGM products. This study uses a discrete choice experiment (DCE) approach to: (1) assess consumer preferences for various processed meat products (including hunted red deer meat bearing a HWGM label); and (2) explore whether consumers' attitude towards AW influence food choice behavior.

This study advances the existing literature in consumer food choice in several ways. First, to the best of our knowledge, despite the interest shown from the EU (for instance EC, 2014), this is the first study exploring how consumers value a quality certification of HWGM. Second, the originality of this study also involves the product of interest. No previous consumer studies have compared consumers' behavior for meat products made with meat from three different animal species (red deer, bovine, and horse). Moreover, no previous food DCE studies analyzed consumer preferences for HWGM and other meat products using a segmentation approach based on consumer AW attitudes. Given the growing consumer interest in AW issues (Verbeke and Viaene, 2000), understanding its role in consumers evaluation of HWGM is a key aspect to predict its future market development. In this sense, the results from this study are relevant for policy makers and stakeholders involved in the HWGM supply chain as they can utilize the findings to design and develop successful marketing strategies and appropriate communication tools aimed at promoting this new market. 
The remainder of the article is organized as follows. First, we introduce a literature review focused on the influence of AW attitudes on consumer's choices. Second, we present the consumer survey design and the estimation procedure followed within the study. Thirdly, the results are described and discussed. Finally, an overview of the research and some conclusions are provided.

\section{The relevance of animal welfare in consumer research}

In the last two decades, AW has become a key attribute that consumers consider when making their food choices (Napolitano et al., 2010; Verbeke, 2009; Verbeke and Viaene, 2000). This is evident in the growing demand of products produced in animal-friendly conditions; such as organic or grass-feed productions (Hölker et al., 2019; Mayfield et al., 2007). Recognizing this trend, the production sector and policy makers have established stricter private and public standards. For example, the production sector has adopted more rigorous standards for laying hens, broiler chickens, gestating sows, and farmed salmon (Diggles et al., 2011; Ellingsen et al., 2015; Ortega and Wolf, 2018; Vecchio and Annunziata, 2012; Verbeke and Viaene, 2000). Similarly, policy makers have developed various legislation in the EU, USA, and South America aiming to better protect livestock (Fraser, 2008; Horgan and Gavinelli, 2006; Napolitano et al., 2010; Norwood and Lusk, 2011; Vargas-Bello-Pérez et al., 2017). However, these efforts have predominantly been focused on traditional livestock such as beef, pork, and chicken (Verbeke, 2009).

One potential explanation for the lack of welfare efforts is that the World Organization for Animal Health (OIE) definition and description of $\mathrm{AW}^{1}$ implies that meat from wild game can have the highest level of AW amongst meat products if harvested under strict and regulated hunting practices (Hoffman and Wiklund, 2006; Marescotti et al., 2019). For instance, wild game meat comes from animals that were born and live in wild conditions without any direct human contact. Furthermore, hunted wild animals are harvested in their natural habitat, thereby eliminating the process of transport and slaughter that cause stress and pain to livestock husbandry (Carlsson et al., 2007; Cockram et al., 2011; Ramanzin et al., 2010; Viganò et al., 2019). Despite this evidence, consumers hold quite controversial opinions about the AW of wild game meat. These opinions likely stem from the link between wild game meat with hunters and hunting practices (Demartini et al., 2018; Hölker et al., 2019; Marescotti et al., 2019). This link may induce consumers to associate HWGM products with low AW standards, leading to a reluctance from consumers to purchase HWGM.

Previous studies have assessed consumer preferences and demand for AW as an attribute of meat products using economic experiments such as experimental auctions (EA) and DCE. These studies can be groups in two main categories: (1) consumer preferences and WTP for meat products produced under different AW standards; and (2) consumer WTP for AW labeling programs. Taken together, the results from these studies indicate that: (a) consumers are willing to pay a price premium for meat products bearing AW claims and labels; and (b) the price premium depends on the consumer's nationality and the animal species, product type, and the type of AW associated with the animal product. Table 1 summarizes the studies by product and methods ${ }^{2}$.

Falling in the first category (studies on consumer preferences and WTP for meat products produced under different AW standards), Carlsson et al. (2007) found that consumers WTP for AW attributes related to transportation of farm animals to slaughterhouses is species-specific and consumers are willing to pay a

\footnotetext{
${ }^{1}$ The OIE defines AW as 'the physical and mental state of an animal in relation to the conditions in which it lives and dies.' and states that 'an animal experiences good welfare if the animal is healthy, comfortable, well nourished, safe, is not suffering from unpleasant states such as pain, fear and distress, and is able to express behaviors that are important for its physical and mental state' (OIE, 2004).

2 The literature review has been carried out using the search engine Google Scholar and Scopus accessed from the Michigan State University and from the University of Milan during June-July 2019. The following keywords have been taken into consideration: animal welfare; animal welfare scale; animal welfare attitudes; choice experiment; experimental auctions. Only papers published in English were taken into account. The only studies judged to be strictly relevant for the research goal were retained $(n=12$; Table 1$)$.
} 
Table 1. Summary of previous studies analyzing consumers' preferences and willingness-to-pay for animal welfare. ${ }^{1}$

\begin{tabular}{|c|c|c|c|c|}
\hline Reference & Product & Method & Country & Key findings \\
\hline $\begin{array}{l}\text { Lagerkvist et al., } \\
2006\end{array}$ & Pork & DCE & Sweden & $\begin{array}{l}\text { Consumers are willing to pay a premium price and } \\
\text { accept potential food safety risk to improve AW }\end{array}$ \\
\hline Carlsson et al., 2007 & $\begin{array}{l}\text { Cattle and } \\
\text { chicken }\end{array}$ & DCE & Sweden & $\begin{array}{l}\text { Consumers' preferences and WTP for AW attributes } \\
\text { related to transportation is species-specific }\end{array}$ \\
\hline Lusk et al., 2007 & Pork & DCE & USA & $\begin{array}{l}\text { Consumers are willing to pay a premium price } \\
\text { for pork meat certified for AW. More altruistic } \\
\text { consumers are willing to pay more than less } \\
\text { altruistic individuals and free riders }\end{array}$ \\
\hline $\begin{array}{l}\text { Liljenstolpe et al., } \\
2008\end{array}$ & Pork & DCE & Sweden & $\begin{array}{l}\text { WTP and preferences for AW attributes are } \\
\text { heterogeneous among respondents and depend on } \\
\text { the individuals' interpretation and attitudes }\end{array}$ \\
\hline Pouta et al., 2010 & Chicken & DCE & Finland & $\begin{array}{l}\text { The probability of consumer choice increase } \\
\text { emphasizing AW in production }\end{array}$ \\
\hline Gracia et al., 2011 & Cured ham & EA & Spain & $\begin{array}{l}\text { Consumers are willing to pay a premium price } \\
\text { between } 19 \text { and } 23 \% \text { for product carrying } \\
\text { an AW label }\end{array}$ \\
\hline Bennet et al., 2012 & $\begin{array}{l}\text { Cattle, pork } \\
\text { and chicken }\end{array}$ & DCE & UK & $\begin{array}{l}\text { Consumers are willing to pay a premium price } \\
\text { of } 16 \% \text { for meat from animals with higher level of } \\
\text { AW. Consumers' WTP for AW attributes is species- } \\
\text { specific }\end{array}$ \\
\hline Nocella et al., 2012 & $\begin{array}{l}\text { Meat, dairy } \\
\text { and eggs }\end{array}$ & $\begin{array}{l}\text { TPB and } \\
\text { DCE }\end{array}$ & $\begin{array}{l}\text { France, } \\
\text { Germany, } \\
\text { Italy, Spain, } \\
\text { UK }\end{array}$ & $\begin{array}{l}74 \% \text { of the sample preferred meat with a higher level } \\
\text { of AW than conventional meat. Consumers were } \\
\text { willing-to-pay a premium price from } 0.30 € / \mathrm{kg} \text { to } \\
0.89 € / \mathrm{kg} \text { for products with a higher level of AW }\end{array}$ \\
\hline $\begin{array}{l}\text { Campbell and } \\
\text { Doherty, } 2013\end{array}$ & Chicken & DCE & UK & $\begin{array}{l}60 \% \text { of the sample were willing to pay a premium } \\
\text { price (ranging from } 0 \text { and over } 2 \text { GBP) for product } \\
\text { with higher AW standards }\end{array}$ \\
\hline Van Loo et al., 2014 & Chicken & DCE & Belgium & $\begin{array}{l}\text { Consumers' are willing to pay a premium price } \\
\text { ranging from } 26 \text { to } 39 \% \text { for products carrying } \\
\text { an AW label }\end{array}$ \\
\hline Grunert et al., 2018 & Pork & DCE & $\begin{array}{l}\text { Germany } \\
\text { and Poland }\end{array}$ & $\begin{array}{l}\text { WTP and preferences for AW attributes are } \\
\text { heterogeneous among respondents and depend on } \\
\text { the individual attitudes }\end{array}$ \\
\hline $\begin{array}{l}\text { Ortega and Wolf, } \\
2018\end{array}$ & $\begin{array}{l}\text { Chicken } \\
\text { and eggs }\end{array}$ & EA & USA & $\begin{array}{l}\text { Consumers WTP for an AW certification is species- } \\
\text { specific and product-specific }\end{array}$ \\
\hline
\end{tabular}

${ }^{1} \mathrm{AW}=$ animal welfare; DCE $=$ discrete choice experiment; $\mathrm{EA}=$ experimental auctions; $\mathrm{TPB}=$ theory of planned behavior; $\mathrm{WTP}=$ willingness-to-pay.

price premium for the use of mobile abattoirs for cattle. Liljenstolpe (2008) evaluated consumers WTP for an array of AW attributes related to housing and managerial practices (i.e. transportation, castration, housing system, type of feed, mixing pigs from different litters, stock density, supply of bedding straw) in pig breeding. Results showed that consumer preferences for AW attributes are heterogeneous among respondents and may be negative or positive depending on the individual's interpretation of managerial practices and expected outcomes. For example, attributes that enhance the well-being of pigs have an impact on food safety and affect environmental concerns of consumers. In addition, Lagerkvist et al. (2006) evaluated Swedish consumers WTP for process attributes related to AW on pork meat (i.e. type of housing system and castration technique). Their findings suggest that consumers are willing to pay a premium price for pork meat that has 
been produced with higher AW conditions. Nevertheless, taste, quality, and sensory characteristics of food products still dominant AW concerns for consumers. Other authors have shown consumers will be willing to pay a higher premium for products that appear to have a higher level of AW. For example, Bennet et al. (2012) found that consumers are willing to pay a premium of $16 \%$ for meat produced from cattle, pigs, and chicken with higher level of AW. Their results also show that consumers' WTP for the attributes of AW is species-specific (higher for cattle) and is positively correlated to their consumption of the different meats. Similar results are found by Pouta et al. (2010), Nocella et al. (2012) and Campbell and Doherty (2013).

As for the second category (studies on consumer WTP for AW labeling programs), Van Loo et al. (2014) investigated Belgian consumers' preferences and WTP for various sustainability claims on chicken meat including AW label. The results from this study indicate that consumers are willing to pay a premium price ranging from 26 to $39 \%$ for products carrying the AW label. Among the other sustainability claims, the AW label was the second most preferred after the free-range claim ( $87 \%$ of the consumers liked it). Similarly, Gracia et al. (2011) found that a hypothetical EU-certification scheme that guarantees superior AW standards increases Spanish consumers' WTP for dry-cured ham between 19 and 23\%. Ortega and Wolf (2018) found that the premium price for an AW certification is species-specific and product-specific (eggs \$1.01/dozen, chicken 1.37/lb., ground pork $\$ 1.09 / \mathrm{lb}$., and pork chops $\$ 1.30 / \mathrm{lb}$ ). Lusk et al. (2007) found that on average consumers are willing to pay a premium price for pork meat certified for AW. In addition, more altruistic consumers are willing to pay more for pork meat certified for animal well-being compared to less altruistic individuals and free riders.

The above discussed studies have focused on a range of domesticated livestock welfare concerns and ignored the HWGM sector. In addition, they assessed how consumers value specific AW attributes and labels on food products but overlooked how individuals' attitudes towards AW issues influence choice behavior for HWGM. To the best of our knowledge, only two studies have focused on HWGM products. Marescotti et al. (2019) identified three consumer segments (pro-animals, disoriented, and HWGM eaters) and showed that consumers who are particularly concerned about AW are less likely to consume HWGM products. Similarly, Hölker et al. (2019) found two groups of consumers with polarized HWGM consumption patterns. The first group is represented by anthropocentric consumers, which think that humans are allowed to do what they want with animals and do not have to consider the welfare. On the other side, the abolitionist consumers constitute the second group and think that the use of animals for human purpose should be prohibited. However, neither of these two studies have specifically considered the impact of consumers' attitudes towards AW on meat selection including HWGM. This study extends the existing literature in this area by studying how consumer attitudes towards AW affect their choice behavior for alternative meat products from different animal species such as red deer, bovine, and horse. It also explores whether a labeling program for HWGM affects consumers' food choice behavior for meat alternatives.

\section{Consumer survey design}

The data was collected through an online survey implemented in Qualtrics ${ }^{\circledR}$ (Provo, UT, USA), a professional online access panel provider, and conducted in Italy. The survey was initially tested through a pilot-study on a sample of 20 respondents (Apostolidis and McLeay, 2016; Green and Gerard, 2009), which allowed us to test the appropriateness of the questions and survey flow. The final sample (168 consumers) included only respondents who have eaten meat in the last three months and are older than 18 years old. Moreover, respondents were asked whether they had consumed wild game meat in the last year and whether they are willing to purchase a cold cuts obtained from red deer meat if would be available on the market. The survey instrument included: (1) choice experiment questions; (2) questions regarding consumers' attitudes towards AW; and (3) socio-demographic questions. The following three subparagraphs describe the experimental procedures followed to implement the DCE, the psychometrics scale used to measure consumer attitude towards AW, and the sociodemographic characteristics of the respondents. 


\subsection{Discrete choice experiment}

The DCE questions were generated using a labelled design. Labelled designs increase the realism of the choice task or choice questions and reproduce shopping scenarios that reflect actual purchase situations (Hensher et al., 2015). In this questionnaire, participants were asked to choose between three alternatives of sliced pack bresaola (100 gr) made with meat from red deer, bovine, and horse. Bresaola is a traditional and wellknown northern Italian processed meat product, obtained through a salting, drying, and aging production method (Braghieri et al., 2009; EC, 1992; Perlasca, 1991). It was chosen as a product of interest because of its high nutritional values (Paleari et al., 2003; Zhang et al., 2018) and the emerging consumer demand for ready-to-eat processed meat products (Paleari et al., 2003; Salghetti 1991, 1998). Moreover, bresaola represents the most common and traditional way to process game meat (Paleari et al., 2003).

While red deer bresaola represents a novel food product, bovine and horse bresaola are the most traditional and common bresaola products sold in Italian grocery stores (Paleari et al., 2003; Zhang et al., 2018). In line with the research objectives, the red deer bresaola was offered with and without a certified hunting supply chain ('Filiera di Caccia Certificata') logo, which was developed for this study. Whereas, the bovine bresaola was offered with and without the EU 'protected geographical indication' (PGI) label as around 12,300 tons out of a total of 17,000 tons bresaola is sold with the PGI label. The inclusion of the PGI labelled bresaola in the choice experiment questions increased the realism of the product. Furthermore, the PGI label underlines the link that exists between the specific geographical region and the product, in which a particular quality, reputation, and other characteristics are attributed to products from their geographical origin. This concept of meat quality is also the basis of the proposed voluntary HVGM labeling. No labels were considered for the horse bresaola since this product does not have any certification of origin (neither Italian nor European) in the Italian market.

In the choice experiment questions, the bresaola products were offered at different price levels, which were selected to reflect the market price of the selected meat products. As for the bovine and horse bresaola, they were selected based on the current prices gathered in Italian supermarket. As for the red deer bresaola, the prices were identified based on information from focus groups, market research, and consultation with experts in the field (butchers and restaurateurs - Gaviglio et al., 2018).

Table 2 summarizes the products and attributes used in the experimental designs. Prior to the choice questions, respondents were faced with a set of information regarding the meaning of the PGI and certified hunting supply chain labels. In addition, due to the hypothetical nature of this study, a cheap talk script (Cummings and Taylor, 1999) was included in the survey preceding the hypothetical valuation questions to minimize potential bias.

A main effects orthogonal fractional design (Louviere et al., 2000) was used to generate the choice questions. Therefore, rather than present all the possible combinations a full factorial design would require, we were able to select a subset of representative choices. The DCE design was generated using Ngene (ChoiceMetrics, 2012).

Table 2. Product attributes and levels for the choice experiment. ${ }^{1}$

\begin{tabular}{llll}
\hline Attributes & Level considered & & \\
\hline ASCs & red deer & bovine & horse \\
Label & HWGM label & PGI label & \\
& none & none & none \\
Price & $5.80 € / 100 \mathrm{gr}$ & $3.99 € / 100 \mathrm{gr}$ & $4.56 € / 100 \mathrm{gr}$ \\
& $8.30 € / 100 \mathrm{gr}$ & $6.49 € / 100 \mathrm{gr}$ & $7.06 € / 100 \mathrm{gr}$ \\
& $10.80 € / 100 \mathrm{gr}$ & $8.99 € / 100 \mathrm{gr}$ & $9.56 € / 100 \mathrm{gr}$ \\
\hline
\end{tabular}

${ }^{1}$ ASCs = alternative specific constants; HWGM = hunted wild game meat; PGI = protected geographical indication. 
The design resulted in 36 choice tasks, instead of 243 (35) choice tasks when including every bresaola product with and without labels (i.e. five alternatives) at every combination of price level (i.e. three price levels). The 36 choice tasks were blocked into four sets of nine and each respondent was randomly assigned to undertake a panel of nine choice tasks. Each block of choice tasks was assessed by the same number of consumers. The ordering of the nine choice tasks was varied across respondents. Therefore, during the survey, the respondents were faced with nine choice questions, and for each choice question they were asked to select which one of the three bresaola alternatives (or none) options they prefer. A choice task example is illustrated in Figure 1.

\subsection{Attitudes towards animal welfare scale}

To detect the consumer attitudes towards AW, the survey included the validated psychometric scale introduced by the Kendall et al. (2006) and adopted by Mayfield et al. (2007), Van Wezemal et al. (2010), Cembalo et al. (2016), and Marescotti et al. (2019). The scale is composed of eight items related to two main AW attitudinal constructs. The first construct is comprised of general ethical issues related to how animal should be treated ('animal treatments'); the second construct focuses on the 'utilitarianism'? , the interrelationships between man and the use of animals, and the obligations that humans have with respect to animals ('animal use') (Cembalo et al., 2016; Mayfield et al., 2007; Mazas et al., 2013). For each item the respondents were asked to express their level of agreement on a 5 -point scale, ranging from ' $1=$ strongly disagree' to ' $5=$ strongly agree' (Table 3 ).

\footnotetext{
${ }^{3}$ Utilitarianism is based on the principle of equality between species. Utilitarianists accept that animal can be used for any purpose as long as their quality of life is guaranteed in accordance with AW principles (Singer, 1989).
}

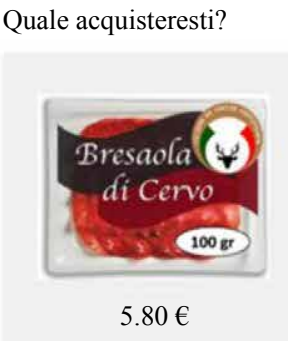

$\bigcirc$

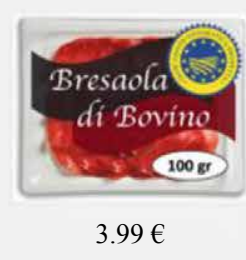

$\bigcirc$

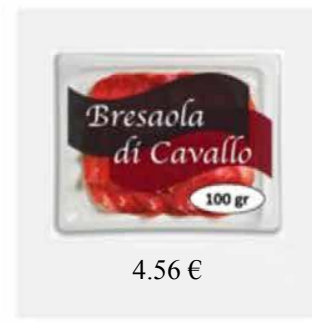

$\bigcirc$

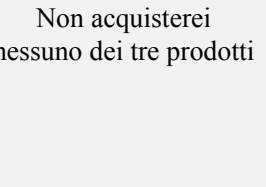

$\bigcirc$

Figure 1. Example of a choice task. The question is translated from the Italian in 'which would you choose?'. The alternative 'Bresaola di Cervo' is the red deer bresaola, the alternative 'Bresaola di Bovino' is the bovine bresaola, the alternative 'Bresaola di Cavallo' is the horse bresaola, while the alternative 'Non acquisterei nessuno dei tre prodotti' is the 'no-buy' option.

Table 3. Attitudes towards animal welfare scale (Kendall et al., 2006).

\section{Express how much you agree or disagree with the following statements: ${ }^{1}$}

1 It is important that the food I normally eat has been produced in a way that animals have not experienced pain.

2 It is important that the food I normally eat has been produced in a way that animals' rights have been respected.

3 In general humans have too little respect for the quality of life of animals.

4 Increased regulation of the treatment of animals in farming is needed.

5 Animal agriculture raises serious ethical questions about the treatment of animals.

6 As long as animals do not suffer pain, humans should be able to use them for any purpose (R).

7 It is acceptable to use animals to test consumer products such as soaps, cosmetics and household cleaners (R).

8 Hunting animals for sport is an acceptable form of recreation (R).

${ }^{1}$ The consumers' agreement with the statement has been measured on a 5-point scale from 1 (strongly disagree) to 5 (strongly agree). Statements marked with ' $R$ ' are negative and were reversed for the final scores. 


\subsection{Sociodemographic characteristics}

The last section of the survey included questions related to the sociodemographic characteristics of the respondents including gender, age, education, income, and region of residence. Table 4 shows the characteristics of our sample and compares it to the Italian population. Most of the respondents were male $(51.19 \%)$ who were between ages of 36 and $55(55.36 \%)$. For most of the respondents the highest level of education was high school $(52.38 \%)$ or university $(38.69 \%)$. Only a small part of the sample has a middle or elementary degree $(8.34 \%)$. Concerning the financial status, a significant portion of the respondents $(35.12 \%)$ declared an average household income between $€ 15,000$ and 29,999. Of the sample, 41.87\% were from the northern part of Italy, $36.31 \%$ were from the southern part of Italy, and $22.62 \%$ live in the central part of Italy. Considering the national characteristics, the sample is slightly biased towards younger and better educated participants, which may be due to the fact that these people are more inclined to participate (Ballco and De Magistris, 2019) and to the use of the online survey method (Hudson et al., 2004).

\section{Data analysis}

The data was analyzed in two steps. Step 1 conducted the analysis of the consumer attitudes towards AW through a principal component analysis (PCA) and a cluster analysis (CA). PCA allowed us to reduce the number of variables of the attitudes towards animal welfare scale (AAW) into a smaller set of uncorrelated principal component or factors. The CA was performed using the factors extracted from the PCA and allowed us to group consumers with similar attitudes towards AW issues into a common segment. Step 2 involved

Table 4. Sociodemographic characteristics of the sample and of the Italian population (\%).

\begin{tabular}{lcc}
\hline & Constant $(\mathbf{n}=\mathbf{1 6 8})$ & Italian population $^{1}$ \\
\hline Gender & & \\
Male & 51.19 & 49.82 \\
Female & 48.81 & 50.18 \\
Age (years) & & \\
$18-22$ & 7.14 & 7.81 \\
$23-35$ & 25.00 & 22.75 \\
$36-55$ & 55.36 & 48.59 \\
$56-65$ & 12.50 & 20.84 \\
Educational level completed & & \\
Elementary school & 0.60 & 5.74 \\
Middle school & 7.74 & 31.95 \\
High school & 52.38 & 44.48 \\
University and Postgraduate & 38.69 & 17.83 \\
Other & 0.60 & - \\
Average household income $(€)$ & & $\mathrm{n} / \mathrm{a}$ \\
$<15,000$ & 13.10 & $\mathrm{n} / \mathrm{a}$ \\
15,000-29,999 & 35.12 & $\mathrm{n} / \mathrm{a}$ \\
30,000-44,999 & 28.57 & $\mathrm{n} / \mathrm{a}$ \\
45,000-59,999 & 7.14 & $\mathrm{n} / \mathrm{a}$ \\
$>60,000$ & 16.07 & 19.05 \\
Geographical region of residence & & 26.22 \\
Northeast Italy & 23.21 & 34.48 \\
Northwest Italy & 17.86 & 19.85 \\
Southern Italy and Islands & 36.31 & \\
Central Italy & 22.62 & \\
\hline & &
\end{tabular}

${ }^{1}$ Authors elaboration based on Italian National Institute of Statistics data (ISTAT, 2018). 
the analysis of the DCE data by estimating a latent class model (LCM) using the results from the first step. More specifically, cluster membership information obtained from the CA were included as covariates in the choice models to investigate the impact of consumers' attitudes towards AW on consumers' preferences for HVGM. Figure 2 shows a schematic representation of the two steps that were followed in the data analysis.

\subsection{Principal component analysis and cluster analysis}

Before performing the PCA, we executed the Kaiser-Meyer-Olkin (KMO) test (Kaiser, 1974) and Bartlett's test of sphericity to measure the correlations among the items and assess the suitability of the data for the factor analysis.

The PCA was performed using the Varimax rotation extraction method and using factors with an eigenvalue greater than 1. It allowed us to define the underlying structure among the items of the AAW scale in order to reduce the number of variables into a smaller set of components (factors). To verify the consistency and the reliability of the PCA extracted factors, the Cronbach's $\alpha$ test (Cronbach, 1951; Peterson, 1994) was performed. The factor scores obtained from the PCA were then used to perform the CA, which allowed us to identify the groups of consumers with similar attitudes towards AW issues. Following previous consumer studies (Bacher et al., 2004; Ballco et al., 2019; Van Loo et al., 2014; Wedel and Kamakura, 2000), we used a two-step procedure. First, we determine the number of clusters by applying the hierarchical clustering procedure. Then, we determined the cluster membership of the respondents by using the non-hierarchical $k$-means analysis. The cluster membership information obtained from the CA were then included in the choice models.

\subsection{Choice experiment}

DCEs are consistent with the random utility theory (RUT) (McFadden, 1974). According to the RUT, individuals facing a set of different alternatives (characterized by certain attributes levels) are assumed to choose the alternative that provides the highest satisfaction or perceived utility (Hanemann and Kanninen, 1999; McFadden, 1974).

The indirect utility function that individual $n$ derives from selecting the alternative $j$ in choice situation $t$ can be described as follows:

$$
U_{n j t}=V_{n j t}+\varepsilon_{n j t}
$$

where $\mathrm{V}_{\mathrm{njt}}$ is the deterministic component of the utility (observed) and $\varepsilon_{\mathrm{njt}}$ is the random error term (unobserved). In this study, the error term is assumed to be independently and identically distributed (IID) across individuals, time, alternatives, and follows a type-I extreme value distribution (Gumbel distribution). Whereas, $V_{n j t}$ is specified as follows:

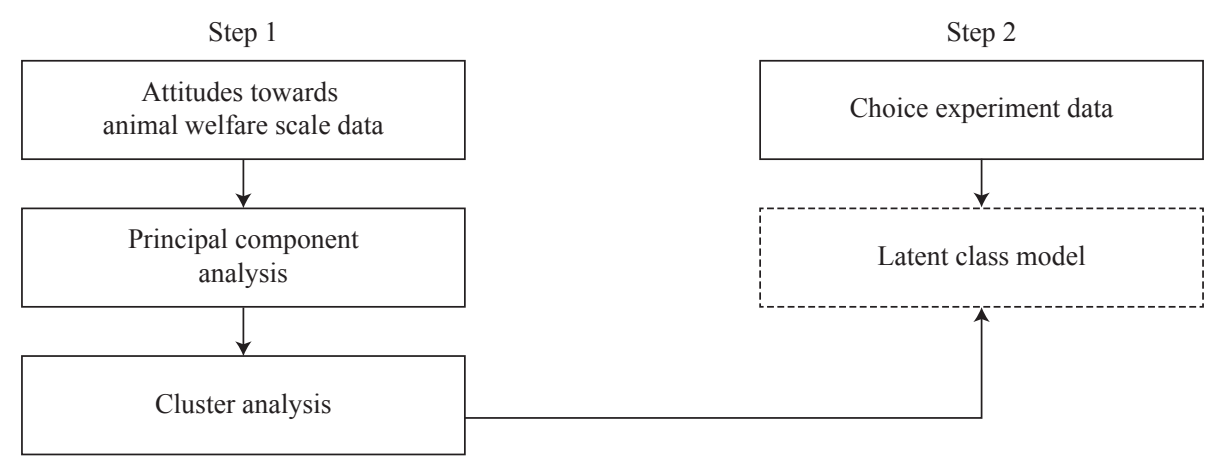

Figure 2. Framework of the analysis. 


$$
V_{n j t}=A S C_{j}+\alpha \text { Price }+\beta_{P G I} P G I_{\mathrm{njt}}+\beta_{\mathrm{HWGM}} \mathrm{HWGM}_{n j t}
$$

where $A S C_{j}$ represent the alternative specific constants for bovine, horse, and red deer bresaola; Price is a continuous variable indicating the price levels for the various products; PGI and HWGM represent the PGI and HWGM labels respectively.

The choice data was estimated using a LCM. The LCM was chosen because it allows us to capture preference heterogeneity across different groups or classes of individuals (Hensher et al., 2015; Train, 2009). The underlying theory of the LCM posits that the $\beta_{i}$ vector of random parameters representing the consumer's preferences are discretely distributed among individuals (Train, 2009). Thus, we assume that the population consists of a finite number of $\mathrm{S}$ classes, each composed of consumers sharing common parameters $\beta_{i}$ within each class (Boxall and Adamowicz, 2002; Hensher et al., 2015). To determine the optimal number of classes we used the Bayesian information criterion (BIC), the minimum Akaike information criterion (AIC), and the modified Akaike information criterion (AIC3). We also explored whether additional segments provide any further economic information- with the overall aim of attaining segment parsimony.

Formally, conditional on belonging to a given class $s$, in the LCM the probability $\operatorname{Pr}_{n}$ of an individual $n$ choosing alternative $j$ in a specific choice situation $t$ from the T set of choice situations, can be expressed as follows:

$$
\operatorname{Pr}_{n(n j t \mid s)}=\prod_{t=1}^{T} \frac{\exp \left(V_{n j t \mid c}\right)}{\sum_{j=1}^{J} \exp \left(V_{n j t \mid c}\right)}
$$

where the elements in $V_{n j t c}$ are specified as in (2). The no-buy alternative has been normalized to equal zero for identification purpose. The alternative-specific attributes (PGI and HWGM) have been effects coded with two levels: +1 when the label is present, -1 when the label is absent. Effect coding is an alternative to dummy coding. It allows us to eliminate any confounding effects between the estimated alternative-specific constants and the coinciding reference level of the attributes zero coded. Therefore, when applying effects coding the reference level is internalised in the $\beta$ estimates. Furthermore, the sign and the magnitude of the estimated coefficients express deviations from the alternative-specific constants (Bech and Gyrd-Hansen, 2005; Molin and Timmersmans, 2010).

\section{Results}

\subsection{Results from the principal component analysis and cluster analysis}

Table 5 reports the descriptive statistics (mean and standard deviation) of the eight AAW scale items. Results indicate that on average, our respondents are highly concerned towards AW (mean value of the total items is 3.72 on a 5-point scale, with a standard deviation of 0.998). This is in line with previous studies reporting that consumers are generally concerned about AW issues (Bennet et al., 2002; Frewer et al., 2005; Marescotti et al., 2019; Mayfield et al., 2007; Napolitano et al., 2010; Toma et al., 2012; Vanhonacker and Verbeke, 2014; Verbeke, 2009). The KMO was 0.835 , which is above the threshold value of 0.6 (Kaiser, 1974). While, the Bartlett's test of sphericity was highly significant $\left(\chi^{2}(28)=639.4 ; P<0.000\right)$. Taken together these results indicate that the AAW scale items are suitable for a PCA analysis. The factor loading reveal a two-dimensional factor structure with eigenvalue higher than 1 , both accounting for $67.57 \%$ of the total variance.

Table 6 reports the rotated component matrix. High factor loading values indicates a greater level of correlation between the factor and the item. The internal consistency of each sub-scale was tested using Cronbach's $\alpha$ test. Both sub-scales showed a high level of reliability (AAW-Fact1 Cronbach's $\alpha=0.880$; AAW-Fact2 Cronbach's $\alpha=0.734)$. These results indicated that our instruments are valid instruments to capture attitudes towards AW related constructs. The first factor is the most influential as it explains the $51.59 \%$ of the total variance. The factor is comprised of five items associated with variables that reveal respondent's concerns 
Table 5. Consumers' attitudes towards animal welfare. ${ }^{1}$

\begin{tabular}{|c|c|c|}
\hline Statements & Mean & $\begin{array}{l}\text { Standard } \\
\text { deviation }\end{array}$ \\
\hline $\begin{array}{l}1 \text { It is important that the food I normally eat has been produced in a way that animals have } \\
\text { not experienced pain. }\end{array}$ & 3.83 & 0.896 \\
\hline $\begin{array}{l}2 \text { It is important that the food I normally eat has been produced in a way that animals' rights } \\
\text { have been respected. }\end{array}$ & 3.95 & 0.857 \\
\hline 3 In general humans have too little respect for the quality of life of animals. & 3.86 & 0.928 \\
\hline 4 Increased regulation of the treatment of animals in farming is needed. & 3.95 & 0.904 \\
\hline 5 Animal agriculture raises serious ethical questions about the treatment of animals. & 3.84 & 0.937 \\
\hline 6 As long as animals do not suffer pain, humans should be able to use them for any purpose (R). & 2.99 & 1.064 \\
\hline $\begin{array}{l}7 \text { It is acceptable to use animals to test consumer products such as soaps, cosmetics and } \\
\text { household cleaners (R). }\end{array}$ & 3.55 & 1.213 \\
\hline 8 Hunting animals for sport is an acceptable form of recreation (R). & 3.80 & 1.187 \\
\hline Mean $=3.72 ;$ Standard deviation $=0.998 ;$ Cronbach's $\alpha=0.851$ & & \\
\hline
\end{tabular}

Table 6. Rotated component matrix. ${ }^{1}$

\begin{tabular}{lcc}
\hline AAW scale items & AAW-Fact1 & AAW-Fact2 \\
\hline 1 & 0.813 & 0.159 \\
2 & 0.840 & 0.232 \\
3 & 0.757 & 0.232 \\
4 & 0.795 & 0.218 \\
5 & 0.824 & 0.100 \\
6 & -0.005 & 0.824 \\
7 & 0.319 & 0.769 \\
8 & 0.340 & 0.733 \\
$\%$ of variance explained & 51.59 & 15.98 \\
& Cronbach's $\alpha=0.880$ & Cronbach's $\alpha=0.734$ \\
\hline 1 Rotation method = varimax with Kaiser normalization; A AW $=$ attitudes towards animal welfare.
\end{tabular}

${ }^{1}$ Rotation method $=$ varimax with Kaiser normalization; AAW = attitudes towards animal welfare.

about the ethical treatments of animals. The second factor, accounting for $15.98 \%$ of the total variance, is comprised of three items related to a more utilitarian orientation related to the use of the animals. As such, the two factors are classified as (1) 'towards animal rights' and (2) 'towards animal utility'. The results are consistent with previous studies reporting that individual attitudes towards animal issues reflects two general coexistent dimensions (Cembalo et al., 2016; Kendal et al., 2006; Paul and Podberscek, 2000). These dimensions include an ethical dimension, devoted to AW issues and animal rights, and a utilitarian dimension, which agrees with the use of animals to produce benefits for humans.

Figure 3 and Table 7 reports the results from the CA, which was performed using the two PCA factors. Two clusters were identified. The first cluster comprises $64.29 \%(n=108)$ of the sample. Consumers belonging to this segment expressed awareness about AW issues and revealed a more ethical behavior. As such, this cluster was termed as 'Animal rights'. The second class, classified as 'Animal utilitarist', includes 35.71\% of the respondents $(\mathrm{n}=60)$. Unlike the first class, consumers in this class show a predominant utilitarian behavior with lower concerns towards AW issues. These results are in line with previous studies reporting that attitudes towards AW are heterogeneous. There is a widely accepted principle that animals should be treated humanely, and cruelty is unacceptable. However, there is also a group of individuals who do not 

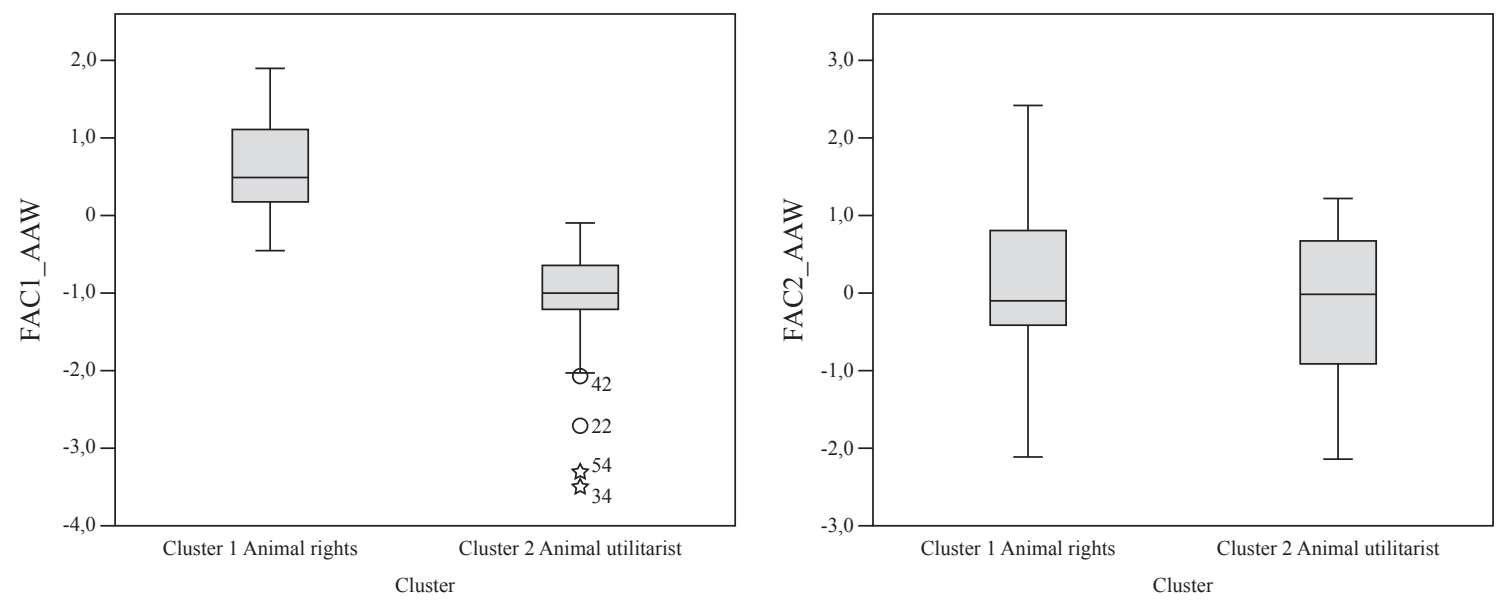

Figure 3. Final Cluster profiles and average scores.

Table 7.

\begin{tabular}{lll}
\hline & $\begin{array}{c}\text { Cluster } \mathbf{1}(\mathbf{n}=\mathbf{1 0 8}) \\
\text { Animal rights }\end{array}$ & $\begin{array}{l}\text { Cluster 2 }(\mathbf{n}=\mathbf{6 0}) \\
\text { Animal utilitarist }\end{array}$ \\
\hline FAC1_AAW: towards animal rights & 0.598 & -1.076 \\
FAC2_AAW: towards animal utility & -0.084 & 0.151 \\
\hline
\end{tabular}

show empathy or sensitivity towards AW issues (Heerwagen et al., 2015; Hölker et al., 2019; Mazas et al., 2013; Schröder and McEachen, 2004).

\subsection{Results from the discrete choice experiment}

The estimation of the LCM was based on 1,512 total observations (168 respondents, each responding to 9 choice tasks) using a panel data structure. To identify the optimal number of classes, we performed a model specification search. The search included estimation of LCM with different number of classes $(2,3,4,5)$. Each of these LCA models also included the results from the CA, namely a dummy variable (CAW) as covariate, which is equal to 1 if respondents belong to cluster 1 (Animal rights), and zero otherwise (Animal utilitarist). The lower the information criterion value (BIC, AIC, 2AIC), the better the model fit. Table 8 presents model fit results.

Looking at the results it can be noted that the model fit improves as we increase the number of latent classes from two to five, thereby indicating that differences exist across the population. However, the model with five classes contain estimated class probabilities that are either smaller than $10 \%$ or statistically insignificant. Therefore, the model with four classes has been selected. Table 9 presents the LCM with four classes estimated parameters.

The LCM results report significant heterogeneity in consumers' preferences across the four latent classes. The first latent class classified as 'cured meat eaters', is the largest class and accounts for $37.4 \%$ of the sample. Cured meat Eaters have a statistically significant (1\% critical level) slightly higher level of utility for the alternative bovine bresaola (5.394), followed by the red deer bresaola (4.515), and by the horse bresaola (3.663). The price coefficient related to this group of consumers $(-0.091)$ shows the lowest value across all consumers' class, meaning that increasing the price will have a lower impact on the utility of this class ( $1 \%$ critical level). The estimated HWGM label coefficient is statistically significant at $5 \%$ critical 
Table 8. Models fit $(\mathrm{n}=1,512){ }^{1}$

\begin{tabular}{llllll}
\hline Models & Classes & Log-likelihood & AIC & AIC3 & BIC \\
\hline LCM 1 & 2 & $-1,402.74$ & $2,833.47$ & $2,847.47$ & $2,907.97$ \\
LCM 2 & 3 & $-1,312.84$ & $2,669.67$ & $2,691.67$ & $2,786.74$ \\
LCM 3 & 4 & $-1,277.50$ & $2,615.00$ & $2,645.00$ & $2,774.64$ \\
LCM 4 & 5 & $-1,197.05$ & $2,470.10$ & $2,508.10$ & $2,672.31$ \\
\hline 1 AIC = Akaike information criterion; AIC3 = Bozdogan Akaike information criterion; BIC = Bayesian information criterion; \\
LCM = latent class model.
\end{tabular}

Table 9. Parameter estimates for latent class model with four classes $(n=1,512) .{ }^{1}$

\begin{tabular}{|c|c|c|c|c|}
\hline \multirow[b]{2}{*}{ Parameters } & \multicolumn{4}{|l|}{ Latent class model } \\
\hline & $\begin{array}{l}\text { Class } 1 \\
\text { 'cured meat eaters' }\end{array}$ & $\begin{array}{l}\text { Class } 2 \\
\text { 'anti-hunting' }\end{array}$ & $\begin{array}{l}\text { Class } 3 \\
\text { 'hunted game meat lovers' }\end{array}$ & $\begin{array}{l}\text { Class } 4 \\
\text { 'price conscious' }\end{array}$ \\
\hline Red deer & $4.515 * * *(6.52)$ & $2.360 *(1.91)$ & $8.193 * * *(9.10)$ & $19.567(0.18)$ \\
\hline Bovine & $5.394 * * *(8.20)$ & $4.798 * * *(7.81)$ & $7.317 * * *(10.56)$ & $17.863(0.17)$ \\
\hline Horse & $3.663 * * *(5.56)$ & $2.920 * * *(4.53)$ & $5.352 * * *(8.84)$ & $18.476(0.17)$ \\
\hline Price & $-0.091 * * *(2.67)$ & $-0.991 * * *(8.50)$ & $-1.057 * * *(9.32)$ & $-0.867 * * *(8.01)$ \\
\hline Hun & $0.482 * *(2.25)$ & $9.504(0.10)$ & $1.176^{* * *}(2.73)$ & $0.545(1.26)$ \\
\hline PGI label & $0.489 * * *(2.58)$ & $0.606^{*}(1.88)$ & $1.441 * * *(3.81)$ & $-0.084(0.15)$ \\
\hline Class probability & 0.374 & 0.256 & 0.192 & 0.178 \\
\hline \multicolumn{5}{|c|}{ THETA in class probability model } \\
\hline Constant & - & $-1.209 * *(2.37)$ & $-0.698(1.62)$ & $-0.427(0.93)$ \\
\hline CAW & - & $1.137 *(1.85)$ & $0.056(0.09)$ & $-0.582(0.86)$ \\
\hline
\end{tabular}

${ }^{1}$ Number if parenthesis are $\mid t$-test $\mid ; * * *, * *, *$ indicates statistical significance at the 1,5 and $10 \%$ level, respectively. CAW $=$ cluster membership.

level and positive (0.482). Considering that the label variables are effects-coded, the sign and the magnitude of the coefficients express deviations from the alternative specific constants. This means that the utility of the purchase option of bovine bresaola increases by 0.482 if the product carries a HWGM label, while it decreases by -0.482 if there is not a HWGM label. This means that this group of consumers increase their level of utility when buying bovine bresaola with the HWGM label by $5.394+0.482=4.997$. Furthermore, the coefficient related to the effect of the presence of the PGI label is statistically significant at $1 \%$ critical level and has a value similar to the HWGM label coefficient (0.489) indicating that the individuals' belonging to this group gain an increase in the utility when purchasing products carrying that label equal to $5.394+$ $0.489=5.883$. For consumers of this class, attitudes towards AW do not appear to be significant in explaining the segmentation, as demonstrated by the insignificance of the CAW coefficient.

The second latent class included $25.6 \%$ of the sample and showed the lowest level of utility for the three product alternatives. Consumers belonging to this class connected the lowest utility coefficient to the product red deer bresaola (2.360), statistically significant at $10 \%$ critical level. The red deer bresaola was followed by the horse bresaola (2.920) and by the bovine bresaola (4.798), both significant at 1\% critical level. Their estimated price coefficient (-0.991) is slightly lower than the other classes of consumers, meaning that are less sensitive to price changing (statistically significant at $1 \%$ critical level). In contrast to the first segment, the label HWGM coefficient is not statistically significant, indicating that the presence of the label on the red deer bresaola does not affect the consumer choice. On the other hand, the estimated coefficient related to the PGI label is statistically significant (1\% critical level) and equal to 0.606 . This means that the utility of the product bovine bresaola carrying a PGI label is thus equal to $4.798+0.606=5.404$. With reference to cluster membership (CAW) related to attitudes towards AW, consumers who are particularly concerned 
about AW are more likely to be in this class (10\% critical level). Considering the results, this class has been defined 'Anti-hunting'.

The third class of consumers, which includes $19.2 \%$ of the respondents, has a statistically significant (1\% critical level) higher level of utility for the red deer bresaola alternative (8.193), followed by the bovine bresaola (7.317), and then by the horse bresaola (5.352). The price coefficient is the most negative across the classes $(-1.057)$, indicating that this group of consumers is more affected to price changing (statistically significant at $1 \%$ critical level). In contrast to the first segment, the estimated coefficients for the effect of the presence of the HWGM label is statistically significant (1\% critical level) and positive (1.176), indicating that the individuals' belonging to this group gain an increase in the utility when purchasing products carrying that label that is equal to $8.193+1.176=9.366$. While the coefficient related to the effect of the presence of the PGI label is statistically significant (1\%) and slightly higher than the coefficient related to the HWGM label (1.441). This means that this group of consumers increase their level of utility when buying bovine bresaola with the PGI label by $7.317+1.441=8.758$. Attitudes towards AW in this case have no influences on the latent class segmentation as indicated by the insignificance of the CAW coefficient. Considering the magnitude of the coefficient related to the product red deer bresaola and to the HWGM label, we refer to this class as 'hunted game meat lovers'.

The fourth and last latent class of consumers is the smallest class extracted by LCM and accounts for 17.8\% of the respondents. It comprises individuals that have been classified as 'Price conscious' since the only coefficient that significantly (1\%) affects their utility is the price. As expected, this coefficient is negative, meaning that increasing the price will have a negative impact $(-0.867)$ on the consumers' utility. Also, for this class of consumers, the attitudes towards AW have no influence on the latent class segmentation.

No significant differences in the socio-demographic characteristics of the four latent class have been identified. This means that profiling the latent class considering the socio-demographic characteristics does not provide any further explanation about the heterogeneity.

\section{Conclusions and final remarks}

Although in Italy HWGM is a widespread traditional product, a regulated Italian labeling scheme certificating the meat origin does not exist. However, since consumers have different perceptions towards hunting, a HWGM label may be controversially judged in terms of AW. It has been widely reported in the literature that consumers' attitudes towards AW affect consumer meat choice behavior and WTP in a different way depending on the animal species and on the products. Therefore, the study of AW issues requires a targeted approach (Napolitano et al., 2010; Vanhonacker et al., 2007).

In this study, we use a CE approach to investigate Italian consumers' preferences for bresaola made with hunted red deer meat and bearing a HWGM label. We consider whether consumers' attitudes towards AW affect their meat choice behavior.

Through a LCM model, we identified four classes of consumers with heterogeneous preferences for cured meat products made with different animal species (red deer, bovine, horse) with different attributes levels. The first class was classified as 'cured meat eaters', because it contains consumers who generally gain utility from the consumption of bresaola products and are less sensitive to price changing. The second class was called 'anti-hunting' because it contains consumers with a predominant ethical dimension that are particularly concerned about AW issues and animal rights, and that consider hunting unacceptable. Consumers of this class associate the lowest level of the utility to the alternative red deer bresaola and the presence of the HWGM label does not provide any benefit to them. On the opposite end of the spectrum, the 'Hunted game meat lovers' class consists of consumers who gain the highest level of utility from the red deer bresaola carrying the HWGM label. The fourth class, termed 'price conscious', consisted of consumers that are strongly influenced by the attribute price and consumers who showed higher preferences for low priced products. 
These four classes showed the different way in which consumers evaluate bresaola products alternatives made with different animal species, with different price levels, and with/without certain labels. Generally, consumers of our sample gained a higher level of utility for products bearing the PGI label when compared to the HWGM label. This is probably due to the PGI label being a well-known certification scheme. On the other hand, preferences for the HWGM label were heterogeneous across the sample. Although the presence of the label HWGM does not provide any added value to consumers who are more concerned for animal rights and more price conscious, more than half of the sample (56.6\%) gain a significant level of utility from choosing red deer bresaola carrying the label (from 0.482 to 1.176). This suggest that, despite the HWGM label not existing on the Italian market, the label has potential and it is appealing to consumers and it will likely be accepted by most of the Italian consumers.

Our results are in line with other studies indicating that consumers have heterogeneous preferences for HWGM (Demartini et al., 2018; Hölker et al., 2019; Marescotti et al., 2019). Although this is the first DCE study that has considered hunted game meat and the effect of attitudes of AW on consumer choice. The classes used within our paper have similarity with the LCA study performed by Grunert et al. (2018). The main finding of this research is that the presence of the HWGM label does not affect negatively consumers more concerned for AW issues and animal rights. While, for the other consumers class, the presence of the label provides an added value that positively affect consumers' choices and that is not correlated with the attitudes towards AW.

Results from this study offers some important implications for the development of marketing strategies and appropriate communication tools able to provide competitive advantage to stakeholders in the supply chain. Considering the increasing consumer concern and public interest in AW issues and environmental impact of the food production, marketing strategies should highlight the positive peculiarity of the hunting production method. For instance, controlled hunting guarantees the highest level of AW, it is a sustainable alternative to intensive livestock production (Marescotti et al., 2019) and, further, it could represent a useful method to control and manage wildlife overpopulation, solving human-wildlife conflicts (Dandi et al., 2011; Giacomelli et al., 2018; Massei et al., 2015). Future policy interventions should involve the development of information campaigns aimed at increasing the consumer awareness about these aspects.

The main limitation of the present research is connected to its hypothetical nature. Once the novel HWGM bresaola becomes available on the market, we would be able to develop a non-hypothetical experiment. Another limitation is the limited number of attributes considered. For further investigation, consumers preferences for HWGM could be interesting avenue if we included other product attributes such as origin, nutritional characteristics (e.g. fat content, $\omega 3 / \omega 6$ ) or carbon footprint within the DCE. Future research might also consider if and how the way consumers perceive other food attributes such food safety and taste influence consumers' preferences for HWGM.

Future research could test the robustness of the obtained results using other meat products or by replicating the study in other countries with different consumer behaviors and ideologies. In addition, future authors could investigate the impacts of the information consumers have about the production methods of their meat.

\section{Acknowledgements}

This research work has been funded by University of Milan - Department of Health, Animal Science and Food Safety (VESPA) 'Piano di Sostegno alla Ricerca 2017 - Linea 2 Azione A)'; and Fondazione Cariplo 'Bandi Ambiente 2016' - Progetto 'Processi di Filiera Eco-Alimentare - La gestione di prodotto sostenibile per lo sviluppo dei territori alpini'. 


\section{References}

Apostolidis, C. and F. McLeay. 2016. Should we stop meating like this? Reducing meat consumption through substitution. Food Policy 65: 74-89.

Arnett, E.B. and R. Southwick. 2015. Economic and social benefits of hunting in North America. International Journal Environmental Study 72: 734-745.

Bacher, J., K. Wenzig and M. Vogler. 2004. SPSS twostep cluster: a first evaluation. Arbeits- und Diskussionpapiere 2(2). University of Friedrich - Alexander, Chair of Sociology, Erlange - Nurnberg, Germany.

Ballco, P., T. De Magistris and V. Caputo. 2019. Consumer preferences for nutritional claims: an exploration of attention and choice based on an eye-tracking choice experiment. Food Research International 116: 37-48.

Ballco, P., T. De Magistris. 2019. Spanish consumer purchase behavior and stated preferences for yoghurts with nutritional and health claims. Nutrients 11: 2742.

Banterle, A. and S. Stranieri. 2008. The consequences of voluntary traceability system for supply chain relationships. An application of transaction cost economics. Food Policy 33(6): 560-569.

Bech, M. and D. Gyrd-Hansen. 2005. Effects coding in discrete choice experiments. Health Economics 14(10): 1079-1083.

Bennet, R.M., A. Kehlbacher and K. Balcombe. 2012. A method for the economic valuation of animal welfare benefits using a single welfare score. Animal Welfare 12(S1): 125-130.

Bennet, R.M., J. Anderson and R.J.P. Blanev. 2002. Moral intensity and willingness to pay concerning farm animal welfare issues and the implications for agricultural policy. Journal of Agricultural and Environmental Ethics 15(2): 187-202.

Bernués, A., Olaizola, A. and K. Corcoran. 2003. Extrinsic attributes of red meat as indicator of quality in Europe: an application for market segmentation. Food Quality and Preferences 14: 265-276.

Boxall, P.C. and W.L. Adanomowicz. 2002. Understanding heterogeneous preferences in random utility models: a latent class approach. Environmental and Resource Economics 23(4): 421-446.

Braghieri, A., A. Girolami, A. Carlucci, N. Piazzolla, A.M. Riviezzi and F. Napolitano. 2009. Sensory properties affecting acceptability of "bresaola" from podolian young bulls. Journal of Sensory Studies 24(5): 677-697.

Byrd, E., J.G. Lee and N.J.O. Widmar. 2017. Perceptions of hunting and hunters by U.S. respondents. Animals 7(11): 83.

Campbell, D. and E. Doherty. 2013. Combining discrete and continuous mixing distributions to identify niche markets for food. European Review of Agricultural Economics 40(2): 287-312.

Carlsson, F., P. Frykblom and J. Lagerkvist. 2007. Consumer willingness to pay for farm animal welfare: mobile abattoirs versus transportation to slaughter. European Review of Agricultural Economics 34(3): 321-344.

Cembalo, L., F. Caracciolo, A. Lombardi, T. Del Giudice, K.G. Grunert and G. Cicia. 2016. Determinants of individual attitudes toward animal welfare-friendly food products. Journal of Agricultural and Environmental Ethics 28(4): 759-765.

Choi, Y.W., J.Y. Lee, D.B. Han and J.R.M. Nayga. 2018. Consumers' valuation of rice-grade labeling. Canadian Journal of Agricultural Economics 66(3): 511-531.

Choice Metrics. 2012. Ngene 1.1.1 user manual and reference guide. Choice Metrics, Sydney, Australia.

Cockram, M.S., D.J. Shaw, E. Milne, R. Bryce, C. McClean and M.J. Daniels. 2011. Comparison of effects of different methods of culling red deer (Cervus elaphus) by shooting on behavior and post mortem measurements of blood chemistry, muscle glycogen and carcase characteristics. Animal Welfare 20: 211-224.

Cronbach, L.J. 1951. Coefficient alpha and the internal structure of tests. Psychometrika 16(3): 297-334.

Cummings, R.G. and L.O. Taylor. 1999. Unbiased value estimates for environmental goods: a cheap talk design for the contingent valuation method. The American Economic Review 89(3): 649-665. 
Dandi, N., S. Ballantyne, D. Moseley, R. Gill, A. Peace and C. Quine. 2011. Preferences for wildlife management methods among the peri-urban public in Scotland. European Journal of Wildlife Research 57: 1213-1221.

Demartini, E., A. Gaviglio and A. Pirani. 2017. Farmers' motivation and perceived effects of participating in short food supply chains: evidence from a North Italian survey. Agricultural Economics 63(5): 204-216.

Demartini, E., D. Vecchiato, T. Tempesta, A. Gaviglio and R. Viganò. 2018. Consumer preferences for red deer meat: a discrete choice analysis considering attitudes towards wild game meat and hunting. Meat Science 146: 168-179.

Diggles, B.K., S.J. Cooke, J.D. Rose and W. Sawynok. 2011. Ecology and welfare of aquatic animals in wild capture fisheries. Reviews in Fish Biology and Fisheries 21(4): 739-765.

Ellingsen, K., K. Grimsrud, H.M. Nielsen, C. Mejdell, I. Olesen, P. Honkanen, S. Navrud, C. Gamborg and P. Sandøe. 2015. Who cares about fish welfare? A Norwegian study. British Food Journal 117(1): 257-273.

European Commission (EC). 1992. Council Regulation (EEC) No 2081/92 of 14 July 1992 on the protection of geographical indications and designations of origin for agricultural products and foodstuffs. Official Journal of the European Union L 208: 1-8.

European Commission (EC). 2000. Regulation (EC) No 1760/2000 of the European Parliament and of the Council of 17 July 2000 establishing a system for the identification and registration of bovine animals and regarding the labelling of beef and beef products and repealing Council Regulation (EC) No 820/97. Official Journal of the European Union L 204: 1-10.

European Commission (EC). 2013. Commission implementing Regulation (EU) No 1337/2013 of 13 December 2013 laying down rules for the application of Regulation (EU) No 1169/2011 of the European Parliament and of the Council as regards the indication of the country of origin or place of provenance for fresh, chilled and frozen meat of swine, sheep, goats and poultry. Official Journal of the European Union L 335: 19-22.

European Commission (EC). 2014. Study on mandatory origin labelling for milk, milk used as an ingredient in dairy products, and unprocessed meat other than beef, pig, poultry, and sheep and goat meat. AGRI-2013-EVAL-03 Study Report Part B - Minor meats. Directorate General for Agriculture and Rural Development, Brussels, Belgium. Available at: https://tinyurl.com/y6twg7hl

Fiala, M., D. Marveggio, R. Viganò, E. Demartini, L. Nonini and A. Gaviglio. 2020. LCA and wild animals: results from wild deer culled in a northern Italy hunting district. Journal of Cleaner Production 244: 118667.

Fraser, D. 2008. Understanding animal welfare. Acta veterinaria Scandinavica 50(S1): 1-7.

Frewer, L.J., A. Kole, S.M.A. Van de Kroon and C. De Lauwere. 2005. Consumers attitudes towards the development of animal-friendly husbandry systems. Journal of Agricultural and Environmental Ethics 18: 345-367.

Gaviglio, A., E. Demartini and M.E. Marescotti. 2017. The creation of a local supply chain for large wild ungulates meat: opportunities and limitation form an Italian alpine case study. Quality - Access to Success 18(S2): 215-222.

Gaviglio, A., M.E. Marescotti and E. Demartini. 2018. The local value chain of hunted red deer meet: a scenario analysis based on a northern Italian case study. Resources 7(2): 34.

Giacomelli, S. and M. Gibbert. 2018. He likes playing the hero - I let her have fun shooting. Gender games in the Italian forest during the hunting season. Journal of Rural Studies 62: 164-173.

Giacomelli, S., Gibbert, M. and Viganò, R. 2018. Community empowerment for managing wild boar. Ecology and Society 23(4): 12.

Gracia, A., M.L. Loureiro and R.M.J. Nayga. 2011. Valuing an EU animal welfare label using experimental auctions. Agricultural Economics 42: 669-677.

Green, C. and K. Gerard. 2009. Exploring the social value of health-care interventions: a stated preference discrete choice experiment. Health Economics 18(8): 951-976.

Grunert, K.G. 2005. Food quality and safety: consumer perception and demand. European Review of Agricultural Economics 32: 369-391. 
Grunert, K.G. 2006. How changes in consumer behavior and retailing affect competence requirements for food producers and processors. Economía Agraria y Recursos Naturales 6(11): 3-22.

Grunert, K.G., W.I. Sonntag, V. Glanz-Chanos and S. Forum. 2018. Consumer interest in environmental impact, safety, health and animal welfare aspects of modern pig production. Results of a cross-national choice experiment. Meat Science 137: 123-129.

Hanemann, W.M. and B. Kanninen. 1999. The statistical analysis of discrete response. In: Bateman, I. and Willis, K. (eds.) Valuing environmental preferences: theory and practice of the contingent valuation method in the US, EU, and developing countries. Oxford University Press, Oxford, UK, pp. 302-441.

Heerwagen, L.R., M.R. Mørkbak, S. Denver, P. Sandøe and T. Christensen. 2015. The role of quality labels in market-driven animal welfare. Journal of Agricultural and Environmental Ethics 28(1): 67-84.

Henchion, M., M. McCarthy, V.C. Resconi and D. Troy. 2014. Meat consumption: trends and quality matters. Meat Science 98: 561-568.

Hensher, D.A., J.M. Rose and W.H. Greene. 2015. Applied choice analysis, second edition. Cambridge University Press, Cambridge, UK.

Hoffman, L.C. and E. Wiklund. 2006. Game and venison: meat for the modern consumer. Meat Science 74: 197-208.

Hölker, S., M. Von Meyer-Höfer and A. Spiller. 2019. Inclusion of animal ethics into the consumer valueattitude system using the example of game meat consumption. Food Ethics 3: 53-75.

Horgan, R. and A. Gavinelli. 2006. The expanding role of animal welfare within EU legislation and beyond. Livestock Science 103: 303-307.

Hudson, D., L.H. Seah, D. Hite and T. Haab. 2004. Telephone presurveys, self-selection, and non-response bias to mail and internet surveys in economic research. Applied Economics Letters 11(4): 237-240.

Italian National Institute of Statistics (ISTAT). 2018. ISTAT demographic balance January 2018. ISTAT, Rome, Italy.

Kaiser, H.F. 1974. An index of factorial simplicity. Psychometrika 39: 31-36.

Kendal, H.A., L.M. Lobao and J.S. Sharp. 2006. Public concern with animal well-being: place, social structural location, and individual experience. Rural Sociology 71(3): 399-428.

Lagerkvist, C.J., F. Carlsson and D. Viske. 2006. Swedish consumer preferences for animal welfare and biotech: a choice experiment. AgBioForum 9(1): 51-58.

Liljenstolpe, C. 2008. Evaluating animal welfare with choice experiment: an application to Swedish pig production. Agribusiness 24(1): 67-84.

Ljung, P.E., S.J. Riley and T.A. Heberlein. 2012. Eat prey and love: game-meat consumption and attitudes toward hunting. Wildlife Society Bulletin 36(4): 669-675.

Louviere, J.L., D.A. Hensher and J.D. Swait. 2000. Stated choice methods. Analysis and applications. Cambridge University Press, Cambridge, UK.

Lusk, J.L., T. Nilsson and K. Foster. 2007. Public preferences and private choices: effect of altruism and free riding on demand for environmentally certified pork. Environmental \& Resource Economics 36: 499-521.

Marescotti, M.E., V. Caputo, E. Demartini and A. Gaviglio. 2019. Discovering market segments for hunted wild game meat. Meat science 149: 163-176.

Massei, G., J. Kindberg, A. Licoppe, D. Gacic, N. Sprem, J. Kamler, E. Baubet, U. Hohmann, A. Monaco, J. Ozolinš, S. Cellina, T. Podgórski, C. Fonseca, N. Markov, B. Pokorny, C. Rosell and A. Náhlik. 2015. Wild boar population up, numbers of hunters down? A review of trends and implications for Europe. Pest Management Science 71: 492-500.

Mayfield, L.E, R.M. Bennet, R.B. Tranter and M.J. Wooldridge. 2007. Consumption of welfare-friendly food products in Great Britain, Italy and Sweden, and how it may be influenced by consumer attitudes to, and behaviour towards, animal welfare attributes. International Journal of Sociology of Food and Agriculture 15(3): 59-73.

Mazas, B., M.R. Fernández Manzanal, F. Javier Zarza and G.A. María. 2013. Development and validation of a scale to assess students' attitude towards animal welfare. International Journal of Science Education 35(11): 1775-1799. 
McFadden, D. 1974. Conditional logit analysis of qualitative choice behavior. In: P. Zarembka (ed.) Frontiers in econometrics. Academic Press, New York, NY, USA, pp. 105-142.

Merlino, V.M, D. Borra, V. Girgenti, A. Dal Vecchio and S. Massaglia. 2018. Beef meat preferences of consumers from Northwest Italy: analysis of choice attributes. Meat Science 143: 119-128.

Molin, E.J.E. and H.J.P. Timmermans. 2010. Context dependent stated choice experiments: the case of train egress mode choice. Journal of Choice Modelling 3(3): 39-56.

Napolitano, F., A. Girolami and A. Braghieri. 2010. Consumer liking and willingness to pay for high welfare animal-based products. Trends in Food Science \& Technology 21: 537-543.

Nocella, G., A. Boecker, L. Hubbard and R. Scarpa. 2012. Eliciting consumer preferences for certified animal friendly foods: can elements of the theory of planned behavior improve choice experiment analysis?. Psychology \& Marketing 29(11): 850-868.

Norwood, F.B. and J.L. Lusk. 2011. A calibrated auction-conjoint valuation method: valuing pork and eggs produced under differing animal welfare conditions. Journal of Environmental Economics and Management 62: 80-94.

Ortega, D.L. and C.A. Wolf. 2018. Demand for farm animal welfare and producer implications: results from a field experiment in Michigan. Food Policy 74: 74-81.

Paleari, M.A., V.M. Moretti, T.M. Beretta and C. Bersani. 2003. Cured products from different animal species. Meat Science 63: 485-489.

Paul, E. and A. Podberscek. 2000. Veterinary education and students' attitudes towards animal welfare. The Veterinary Record 146(10): 269-272.

Perlasca, M. 1991. La preparazione della bresaola. Ingegneria Alimentare 3: 11-12.

Peterson, R.A. 1994. A meta-analysis of Cronbach's coefficient alpha. Journal of Consumer Research 21: 381-391.

Pouta, E., J. Heikkilä, S. Forsman-Hugg, M. Isoniemi and J. Mäkelä. 2010. Consumer choice of broiler meat: the effects of country of origin and production methods. Food Quality and Preferences 21: 539-546.

Ramanzin, M., A. Amici, C. Casoli, L. Esposito, P. Lupi, G. Marsico, S. Mattiello, O. Olivieri, M.P. Ponzetta, C. Russo and M. Trabalza Marinucci. 2010. Meat from wild ungulates: ensuring quality and hygiene of an increasing resource. Italian Journal of Animal Science 9(61): 318-331.

Salghetti, A. 1991. Elementi strutturali ed economici degli allevamenti di ungulati selvatici in Italia. Annali Facoltà Medicina Veterinaria Università di Parma 11: 87-173.

Salghetti, A. 1998. Aspetti economici dell'allevamento del cinghiale. Annali Facoltà Medicina Veterinaria Università di Parma 18: 143-161.

Schröder, M.J. and M.G. McEachern. 2004. Consumer value conflicts surrounding ethical food purchase decisions: a focus on animal welfare. International Journal of Consumer Studies 28(2): 168-177.

Singer, P. 1989. All animals are equal. In: T. Regan and P. Singer (eds.) Animal rights and human obligations. Prentice Hall, Englewood Cliffs, NJ, USA, pp. 73-86.

Thogmartin, W. 2006. Why not consider the commercialization of deer harvests? Bioscience 56: 957.

Toma, L., A.W. Stott, C. Revoredo-Giha and B. Kupiec-Teahan. 2012. Consumers and animal welfare, a comparison between European Union countries. Appetite 58: 597-607.

Train, K.E. 2009. Discrete choice methods with simulation. Cambridge University Press, Cambridge, UK.

Van Loo, E., V. Caputo, R. Nayga and W. Verbeke. 2014. Consumers' valuation of sustainability labels on meat. Food Policy 49(1): 137-150.

Van Wezemal, L., W. Verbeke, J.O. Kügler, M.D. de Barcellos and K.G. Grunert. 2010. European consumers and beef safety: perceptions, expectations and uncertainty reduction strategies. Food Control 21: 835-844.

Vanhonacker, F. and W. Verbeke. 2014. Public and consumer policies for higher welfare food products: challenges and opportunities. Journal of Agricultural and Environmental Ethics 27: 153-171.

Vanhonacker, F., W. Verbeke, E. Van Poucke and F.A.M. Tuyttens. 2007. Segmentation based on consumers' perceived importance and attitude toward farm animal welfare. International Journal of Sociology of Food and Agriculture 15(3): 84-100. 
Vargas-Bello-Pérez, E., G.C. Miranda-de la Lama, D. Leimos Teixeira, D. Enriquez-Hidalgo, T. Tadich and J. Lensink. 2017. Farm animal welfare influences on markets and consumer attitudes in Latin America: the cases of Mexico, Chile and Brazil. Journal of Agricultural and Environmental Ethics 30: 697-713.

Vecchio, R. and A. Annunziata. 2012. Italian consumer awareness of layer hens' welfare standards: a cluster analysis. International Journal of Consumer Studies 36: 647-655.

Verbeke, W. 2001. The emerging role of traceability and information in demand-oriented livestock production. Outlook on Agriculture 30: 249-255.

Verbeke, W. 2009. Stakeholder, citizen and consumer interests in farm animal welfare. Animal Welfare 18: 325-333.

Verbeke, W. and J. Viaene. 2000. Ethical challenges for livestock production: meeting consumer concerns about meat safety and animal welfare. Journal of Agricultural and Environmental Ethics 12: 141-151.

Verbeke, W. and R.W. Ward. 2006. Consumer interest in information cues denoting quality, traceability and origin: an application of ordered probit models to beef labels. Food quality and Preferences 17: 453-467.

Viganò, R., E. Demartini, F. Riccardi, A. Corradini, M. Besozzi, P. Lanfranchi, P.L. Chiappini, A. Cottini and A. Gaviglio. 2019. Quality parameters of hunted game meat: sensory analysis and $\mathrm{pH}$ monitoring. Italian Journal of Food Safety 8(1): 7724.

Wedel, M. and W.A. Kamakura. 2000. Market segmentation: conceptual and methodological foundations, $2^{\text {nd }}$ edition. Springer, New York, NY, USA.

World Organisation for Animal Health (OIE). 2004. Terrestrial animal health code. OIE, Paris, France.

Zhang, R., M.J. Yoo, J. Gathercole, M. Gomes Reis and M.M. Farouk. 2018. Effect of animal age on the nutritional and physicochemical qualities of ovine bresaola. Food Chemistry 254: 317-325. 